Published in final edited form as:

Gend Med. 2008 ; 5(Suppl A): S103-S113. doi:10.1016/j.genm.2008.03.010.

\title{
Estrogens and the Diabetic Kidney
}

\author{
Christine Maric, $\mathbf{P h D}^{1,2}$ and Shannon Sullivan, MD, PhD ${ }^{1}$ \\ ${ }^{1}$ Department of Medicine, Georgetown University Medical Center, Washington, DC \\ ${ }^{2}$ Center for the Study of Sex Differences in Health, Aging and Disease, Georgetown University \\ Medical Center, Washington, DC
}

\begin{abstract}
Background-Across all ages, the incidence and rate of progression of most nondiabetic renal diseases are markedly higher in men compared with age-matched women. These observations suggest that female sex may be renoprotective. In the setting of diabetes, however, this female protection against the development and progression of renal disease is diminished.
\end{abstract}

Objective-This review aimed to summarize our current understanding of sex differences in the development and progression of diabetic renal disease, and of the contribution of sex hormones, particularly estrogens, to the pathophysiology of this disease. We also attempted to answer why female sex does not protect the diabetic kidney.

Methods-The review employed PubMed as a search database using terms such as gender, sex, diabetes, diabetic nephropathy, estrogens, sex hormones, as well as targeted searches such as gender/sex differences in diabetic renal disease. Manuscripts identified from cited references were also used. Searches were restricted to English-language articles, while no restrictions were imposed on the publication dates.

Results-Although the existing data regarding the sex differences in the incidence and progression of diabetic renal disease are inconclusive, the undisputed fact is that women with either type 1 or type 2 diabetes mellitus exhibit a much higher incidence of renal disease compared with nondiabetic women. It is conceivable that the loss of female sex as a renoprotective factor in diabetes may be related to the abnormal regulation of sex hormone concentrations. Both clinical and experimental data suggest that diabetes may be associated with an imbalance in estradiol concentrations. Supplementation with $17 \beta$-estradiol or administration of selective estrogen receptor modulators reduces the incidence of diabetes and attenuates the progression of diabetic renal disease.

Conclusions-Serum concentrations of ovarian hormones may provide a new means for predicting future risk of renal complications in diabetes. Exogenous steroid hormones may be an effective treatment for attenuating the progression of diabetic nephropathy.

\section{Keywords}

estrogen; diabetes; diabetic nephropathy; sex hormones 


\section{INTRODUCTION}

Numerous studies have found that nondiabetic premenopausal women have a lower risk for developing chronic kidney disease and a slower rate of progression to end-stage renal disease compared with age-matched nondiabetic men. ${ }^{1-4}$ This disparity appears to be independent of hypertension, dietary protein, serum cholesterol concentrations, and in most cases, the etiology of renal disease. ${ }^{4,5}$ These observations suggest that female sex, at least before menopause, may be protective, and that male sex may be a risk factor for the development and progression of nondiabetic renal disease. However, in the setting of diabetes mellitus (DM), this sex difference in the incidence and progression of renal disease has not been fully established. Whereas some studies report that male sex is a risk factor for the development and progression of renal disease in diabetes, ${ }^{6-10}$ others indicate no sex differences ${ }^{11,12}$ or even increased risk in women. ${ }^{13-16}$ The reasons for these contradictory reports are numerous, including different patient populations studied, different study designs, and inadequate analysis.

Regardless of whether sex differences exist in the incidence and rate of progression of diabetic renal disease, the intriguing issue is the actual differences in diabetic renal disease between age-matched nondiabetic and diabetic women. Whereas the incidence of nondiabetic renal disease in premenopausal women is fairly low, diabetes dramatically increases the risk for developing renal disease. ${ }^{2,3}$

The aim of this review was to summarize our current understanding of sex differences in the development and progression of diabetic renal disease, and of the contribution of sex hormones, particularly estrogens, to the pathophysiology of this disease. We also explored why the protective factor of female sex is lost in the development and progression of renal disease in diabetes.

\section{METHODS}

Using PubMed as a database, articles were searched for using terms such as gender, sex, diabetes, diabetic nephropathy, estrogens, sex hormones, as well as targeted searches such as gender/sex differences in diabetic renal disease. Manuscripts identified from cited references were also used. Searches were restricted to English-language articles, while no restrictions were imposed on the publication dates.

\section{SEX DIFFERENCES IN THE INCIDENCE AND PROGRESSION OF DIABETIC RENAL DISEASE}

Most epidemiologic and experimental studies indicate that the rates of development and progression of nondiabetic renal disease are far lower in premenopausal women compared with age-matched men. ${ }^{1-4}$ In contrast, the contribution of sex to diabetic renal disease is poorly understood. The existing data are contradictory: studies report that diabetic females progress either at a faster rate ${ }^{6-10}$ or a slower rate ${ }^{13-16}$ than age-matched diabetic men, or that there are no sex differences in the rate of progression. ${ }^{11,12}$ This lack of conclusive data on the effects of sex on diabetic renal disease reflects the fact that few studies have addressed this issue and that the studies that did were limited by differences in study populations and methodology and by not specifically addressing factors such as age, hormonal status, duration and type of diabetes, ethnicity, demographic characteristics, blood pressure, blood glucose control, or antihypertensive therapy. 


\section{Sex Differences in Diabetic Nephropathy Associated with Type 1 Diabetes Mellitus}

In a large cross-sectional study of a cohort of normotensive patients with type $1 \mathrm{DM}$ (mean age, 24 years) with either no or mild chronic kidney disease (serum creatinine concentration $<1.5 \mathrm{mg} / \mathrm{dL}$ ), by univariate analysis, male sex was found to be a risk factor for the development of microalbuminuria and macroalbuminuria. ${ }^{17}$ This association was not as strong in a multivariate model. In another cohort of type $1 \mathrm{DM}$ patients of comparable mean age, a more complex association between sex and renal disease progression was found. Although female sex was found to be a risk factor for the development of microalbuminuria, this was apparent only in women with shorter-term diabetes, and the risk decreased with duration of diabetes. ${ }^{14}$ Unfortunately, this study did not analyze the data using a multivariate model, making it difficult to compare the study to that by Mangili et al. ${ }^{17}$

Several studies that examined the effects of sex on the development and progression of diabetic renal disease in type $1 \mathrm{DM}$ prospectively reported conflicting findings. In a randomized trial of captopril in type $1 \mathrm{DM}$, no effects of sex on the course of diabetic renal disease was observed after a 3 -year follow-up. ${ }^{11,18}$ Similarly, no effects of sex on the progression of diabetic renal disease over 2 years were observed in a prospective study examining the effects of smoking ${ }^{19}$ or in a Danish cohort of normoalbuminuric patients followed for 11 years. ${ }^{12}$ Male sex was found to be associated with a decline in glomerular filtration rate over 5 years in a prospective study of a smaller cohort of patients with established diabetic nephropathy. ${ }^{10}$ In the Diabetes Control and Complications Trial/ Epidemiology of Diabetes Interventions and Complications study, ${ }^{8}$ male sex was a risk factor for microalbuminuria, but this effect disappeared when adjusted for waist-hip ratio, suggesting a role for visceral adiposity in the development of diabetic nephropathy in type 1 DM. A complex relationship between sex and renal disease progression was reported in the Pittsburgh Epidemiology of Diabetes Complications Study. ${ }^{20}$ In normoalbuminuric patients followed for 2 years, hemoglobin $\mathrm{A}_{1 \mathrm{C}}\left(\mathrm{HbA}_{1 \mathrm{C}}\right)$ concentration, age, and baseline albumin excretion rates were predictors of disease progression in men, whereas for women, the main predictors were duration of diabetes and triglyceride concentrations. Short stature associated with low birth weight has been reported to be related to development of diabetic nephropathy in men. ${ }^{21}$ These observations suggest that the mechanisms and factors contributing to the development and/or progression of diabetic nephropathy may be sexspecific.

Several studies have also reported that female sex is a risk for the development of diabetic nephropathy. In a large cohort of adolescents with type $1 \mathrm{DM}$, female sex was reported to contribute to microalbuminuria independently of duration of diabetes. ${ }^{16}$ In children who develop type 1 DM before the age of 16 years, the adjusted proportional probability of developing microalbuminuria was found to be greater in females than in males. ${ }^{15}$ Mortality rates in type $1 \mathrm{DM}$ appear to be higher among females, at least in Israel and Sweden, ${ }^{13,22}$ and the prevalence of nephropathy in patients who die is greater in females than in males. ${ }^{13}$

Given the numerous differences in these studies with respect to duration of diabetes, age group, and definition of disease progression, it is not surprising that conflicting findings regarding the effects of sex on the progression of diabetic nephropathy associated with type 1 DM have been reported. However, even though these studies do not provide a conclusive answer to the question of whether sex differences exist in the development and/or progression of diabetic renal disease associated with type $1 \mathrm{DM}$, they do indicate that the mechanisms leading to the disease development and progression may be sex specific. Further supporting the notion that there may be sex differences in the pathophysiology of the disease is the finding of a functional polymorphism in the regulated on activation, normal Tcell expressed and secreted (RANTES) receptor gene (CCR5). ${ }^{23}$ This polymorphism is associated with increased risk of diabetic nephropathy in type $1 \mathrm{DM}$, but only in men. It is 
likely that future studies will reveal other sex-specific functional polymorphisms in genes involved in the pathogenesis of diabetic nephropathy.

\section{Sex Differences in Diabetic Nephropathy Associated with Type 2 Diabetes Mellitus}

Similar to type1 DM, the effects of sex on the development and progression of diabetic renal disease are also unclear in type 2 DM. In a cross-sectional analysis of a large, multicenter, randomized, controlled trial looking at the effects of intensive versus moderate blood pressure control on diabetic complications, males had a greater prevalence of microalbuminuria and macroalbuminuria than did females. ${ }^{24}$ However, because multivariate analysis was not performed in this study, it is unclear whether the observed effect of sex on the prevalence of albuminuria was independent of other factors. In 2 separate prospective studies, the prevalence of albuminuria was reported to be significantly higher in males than in females. ${ }^{25,26}$ However, here again the effect of sex on the prevalence of albuminuria was not assessed using a multivariate model.

In contrast to findings of these studies, in the Irbesartan in Diabetic Nephropathy Trial $(\text { IDNT })^{27}$ and the Reduction in End Points in NIDDM with the Angiotensin II Receptor Antagonist Losartan study, ${ }^{28}$ renal disease was reported to progress at a faster rate in females compared with males. Furthermore, the IDNT also found that women benefited less from treatment with irbesartan than did men. However, most of the women included in these trials were postmenopausal, and hormonal status may play a significant role in determining both the effectiveness of treatment and disease progression. In a prospective observational study of a cohort of white patients with type 2 DM followed for a median of 5.8 years, male sex was found to be a risk factor for the development of incipient (persistent microalbuminuria) and overt (persistent macroalbuminuria) diabetic nephropathy. ${ }^{29}$ Unlike type $1 \mathrm{DM}$, where short stature related to low birth weight was shown to increase the risk of developing diabetic nephropathy in men, a study in a large population-based sample of newly diagnosed type $2 \mathrm{DM}$ patients (aged $>40$ years) noted a relationship between short stature and development of diabetic nephropathy in women, but not in men. ${ }^{30}$

These studies do not provide a conclusive answer as to whether there are sex differences in the development and/or progression of diabetic renal disease associated with type 2 DM. What is more disturbing, however, is that most of these studies did not seem to acknowledge that hormonal status may play a role in the disease process. Addressing this issue in future studies, or at least in meta-analyses of the existing data, may provide more conclusive findings on the effects of sex in diabetic nephropathy associated with type 2 DM.

The data seem to be more conclusive in some racial minorities. In African Americans, Hispanics, and Pima Indians, women are at greater risk for developing type $2 \mathrm{DM}$ and associated end-stage renal disease than are men. ${ }^{31-33}$ These women also have a higher mortality rate from heart disease than do men. ${ }^{34,35}$ In American Indians, using analysis models controlled for age, treatment with oral hypoglycemic agents, $\mathrm{HbA}_{1 \mathrm{C}}$ concentration, blood pressure, obesity, and duration of diabetes, low concentrations of high-density lipoproteins were reported to be a risk factor for the development of albuminuria in women but not in men with type $2 \mathrm{DM} .{ }^{36}$ These observations suggest that, similar to type $1 \mathrm{DM}$, different mechanisms may be responsible for the development of diabetic nephropathy in women and men. Furthermore, the mechanisms underlying the disease process are also likely to be specific for different ethnic groups and races.

In summary, several studies have reported sex differences in the development and/or progression of diabetic nephropathy associated with either type $1 \mathrm{DM}$ or type $2 \mathrm{DM}$. However, due to differences in study design, analysis, and patient population, we still lack a conclusive answer to whether sex plays a role in the development and/or progression of the 
disease. Most disturbing, current literature gives the impression that it is already well established that the incidence and rate of progression of diabetic renal disease are far lower in women than in men. Such a belief may hinder future studies from even examining the potential effects of sex in diabetic nephropathy. In truth, we are far from having a conclusive answer as to whether or not sex impacts the course of diabetic renal disease. Further studies are warranted to properly address this issue by focusing on one of the factors that has commonly been neglected in previous studies - the fundamental differences in hormonal status in women and men.

\section{RELATIONSHIP BETWEEN SEX HORMONES, DIABETES, AND DIABETIC NEPHROPATHY}

\section{Sex Hormones and Diabetes}

The incidence and progression of renal disease in premenopausal nondiabetic women are far lower compared with age-matched non-diabetic men. ${ }^{1-4}$ This relationship is not as apparent postmenopausally. The popular belief is that postmenopausal women lose female sex as a protective factor at menopause, after which they exhibit a prevalence of nondiabetic renal disease that is similar to that of men. However, no adequate data firmly establish this relationship. In addition, unlike in nondiabetic renal disease in which women appear to be protected at least premenopausally, this protection is diminished in the setting of diabetes. The incidence of renal disease associated with both type 1 and type $2 \mathrm{DM}$ is far greater in diabetic compared with nondiabetic women, both pre- and postmenopausally. ${ }^{1-4}$ Thus, if female sex hormones are protective of the nondiabetic kidney, the question is why they are no longer renoprotective in the setting of diabetes.

Several studies have suggested that circulating estradiol concentrations are decreased in women with type $1 \mathrm{DM},{ }^{37-39}$ suggesting that diabetes may be associated with dysregulation of sex hormone biosynthesis. Similar observations were made in experimental models of type $1 \mathrm{DM} .{ }^{40,41}$ Further supporting the link between sex hormones and diabetes are the observations that women with type $1 \mathrm{DM}$ have impaired ovarian function, delayed age at menarche, are at a higher risk for having menstrual irregularities, and have a higher risk of adverse pregnancy outcomes (eg, spontaneous abortions, stillbirths, and congenital anomalies) than age-matched nondiabetic women. ${ }^{37,42,43}$ These observations suggest that type $1 \mathrm{DM}$ is associated with dysregulation of sex hormones, and it is conceivable that reduced estradiol concentrations may be responsible for the loss of female sex as a protective factor, at least in type $1 \mathrm{DM}$.

The data are more confusing when it comes to type 2 DM. A recent meta-analysis examining the concentrations of endogenous sex hormones in postmenopausal women reported that elevated plasma estradiol and decreased sex hormone-binding globulin (SHBG) concentrations internally controlled for body mass index were associated with an increased risk for type $2 \mathrm{DM}^{44}$ This observation is surprising, given the postmenopausal status of these women, and also suggests a potential detrimental effect of estrogen in diabetes. In contrast, decreased plasma estradiol concentrations were reported in nonobese premenopausal women with type $2 \mathrm{DM} .{ }^{45}$ Although further studies are needed to properly evaluate plasma estradiol concentrations in diabetic women, most clinical and experimental studies found that there were beneficial effects of estrogens in diabetes and that hormone therapy (HT) may prevent the onset of diabetes.

\section{Hormone Therapy and Diabetes}

Several clinical studies have evaluated the effect of HT on glucose metabolism and the incidence of diabetes. In a large, randomized, double-blind, placebo-controlled trial in 
postmenopausal women with coronary heart disease, treatment with conjugated equine estrogen in conjunction with medroxyprogesterone reduced the incidence of diabetes by $35 \%$ over 4 years. ${ }^{46}$ Similar beneficial effects were observed in healthy postmenopausal women with type $2 \mathrm{DM}$ : treatment with either estrogen alone or with medroxyprogesterone improved glycemic control and lipid metabolism and decreased carotid wall thickness and atherosclerosis. ${ }^{47-51}$ In addition, the selective estrogen receptor modulator raloxifene has been found to have favorable effects on concentrations of triglycerides and low-density lipoprotein in women with type 2 DM. ${ }^{52}$ Based on these findings, HT appears to be beneficial in type $2 \mathrm{DM}$; however, very few studies to date have examined the effects of HT on diabetic end-organ complications, including diabetic nephropathy.

\section{Estrogens and Diabetic Nephropathy}

Several studies found that pubertal status had a significant effect on the prevalence of microalbuminuria. In patients diagnosed with diabetes before puberty, there is a latent period followed by rapid development of microalbuminuria. ${ }^{53,54}$ In contrast, in patients diagnosed with diabetes at or after puberty, microalbuminuria is constant over time. These observations imply an association between onset of sexual maturity and the development and progression of diabetic nephropathy. Short-term administration of estrogen alone ${ }^{55,56}$ or together with norgestrel (a synthetic progestin) was found to reduce proteinuria and improve creatinine clearance in diabetic and hypertensive postmenopausal women. ${ }^{57}$ Short-term treatment with raloxifene limits the progression of albuminuria in postmenopausal women with type 2 DM. ${ }^{58}$ In experimental models, the data were inconclusive. In the diabetic Otsuka Long-Evans Tokushima Fatty rat, treatment with $17 \beta$-estradiol $\left(\mathrm{E}_{2}\right)$ had no effect on albuminuria, but decreased mesangial expansion and glomerulosclerosis. ${ }^{59}$ Other studies found that treatment with $\mathrm{E}_{2}$ from the onset of diabetes reduced albuminuria, glomerulosclerosis, and tubulointerstitial fibrosis, ${ }^{60-62}$ suggesting that $\mathrm{E}_{2}$ may be renoprotective. Similar to humans, treatment with raloxifene in experimental models attenuated albuminuria and the renal structural damage associated with diabetes. ${ }^{62,63}$

Experimental studies also indicate that estrogen receptor $\alpha$ is abnormally regulated in the diabetic kidney 40,41 and, coupled with the abnormal regulation of its ligand, ${ }^{40,41}$ contributes to the progression of diabetic renal disease. Indeed, a recent study reported an association between introns 1 and 2 of the estrogen receptor- $\alpha$ gene and diabetic nephropathy in African-American and European-American populations, ${ }^{64}$ further stressing the potential importance of sex hormones and their receptors in the pathophysiology of diabetic nephropathy.

Not all studies, however, support the beneficial effects of estrogens in the diabetic kidney. A recent study reported a positive correlation between elevated serum concentrations of phytoestrogens and the severity of diabetic renal disease, suggesting either a detrimental effect of phytoestrogens or the inability of the diabetic kidney to use phytoestrogens to its advantage. ${ }^{65}$ The use of oral contraceptives containing high doses of estrogen has been linked to the development of macroalbuminuria. ${ }^{66}$ However, another study using oral contraceptives containing low-dose estrogen did not observe any effects on urine albumin excretion. ${ }^{67}$ These observations not only point to the importance of the doses of estrogen used, but more significantly, to the importance of the timing of HT. If diabetes is indeed associated with reduced plasma estradiol concentrations, a prolonged period of hypestrogenicity is likely to be associated with an adapted state in which the actions of estrogens are downregulated. It is conceivable that administration of high doses of estrogen under such circumstances may lead to overactivation of cellular pathways regulated by estrogen, resulting in a detrimental effect. 
Overall, there is strong evidence to suggest that estrogens and HT may have beneficial effects in diabetes. Further studies are warranted to examine in detail the specific effects of estrogens in diabetic nephropathy.

\section{MECHANISMS OF ACTION OF ESTROGENS IN THE KIDNEY}

Even though few studies have directly examined the effects of estrogens in diabetic nephropathy, numerous reports indicate that $\mathrm{E}_{2}$ modulates cellular processes in the kidney that are involved in the pathophysiology of the disease. In both the diabetic and nondiabetic kidney, $E_{2}$ attenuates glomerulosclerosis and tubulointerstitial fibrosis by reducing synthesis of type I and type IV collagen, increasing expression of matrix metalloproteinases, and inhibiting apoptosis. ${ }^{60,61,68-70}$ Furthermore, $\mathrm{E}_{2}$ decreases the expression of transforming growth factor- $\beta$, angiotensin AT1 receptor and endothelin-1, all of which stimulate abnormal cell growth and extracellular matrix metabolism and contribute to the vascular dysfunction associated with renal disease. ${ }^{60,71-74} \mathrm{E}_{2}$ has also been shown to upregulate nitric oxide synthase activity and vascular endothelial growth factor expression in the glomerulus. ${ }^{75}$ Both of these factors regulate vascular permeability and thereby could contribute to the loss of glomerular function in progressive chronic kidney disease, including diabetic nephropathy. Selective estrogen receptor modulators have renoprotective effects that are similar to those of $E_{2}$ in suppressing collagen type I and IV synthesis, promoting matrix metalloproteinase activity, and inhibiting transforming growth factor- $\beta$ protein expression. ${ }^{76}$ There is also a growing body of evidence suggesting that metabolites of $\mathrm{E}_{2}, 2$ methoxyestradiol in particular, mediate the beneficial effects of $\mathrm{E}_{2}$, but without the feminizing side effects. In obese diabetic ZSF1 rats, 2-methoxyestradiol attenuated the development of obesity, metabolic syndrome, and vascular and renal dysfunction by inhibiting cell proliferation and extracellular matrix synthesis. ${ }^{77,78}$ These studies clearly indicate that estrogens have a beneficial effect in the kidney. Future studies are likely to yield important information about the precise role for estrogens in the pathophysiology of diabetic renal disease.

\section{ANDROGENS, DIABETES, AND DIABETIC NEPHROPATHY}

Although a specific role for androgens in diabetes and/or diabetic nephropathy has not been elucidated, many studies show a positive relationship between androgens and insulin resistance or type $2 \mathrm{DM}$. In both premenopausal and postmenopausal women, hyperandrogenicity is correlated with insulin resistance and type $2 \mathrm{DM},{ }^{79,80}$ and has been found to be an independent risk factor for the development of type 2 DM. ${ }^{81,82}$ A large metaanalysis of sex differences in type $2 \mathrm{DM}$ showed that increased testosterone concentrations and decreased concentrations of SHBG, an independent marker of hyperandrogenicity, predicted an increased risk of type $2 \mathrm{DM}$ in postmenopausal women, but that risk of type 2 DM was higher in men with low testosterone and high SHBG concentrations. ${ }^{44}$ Consistent with these findings, low SHBG concentrations (and thus high androgen concentrations) predicted development of type 2 DM in premenopausal women, but SHBG was not predictive of type $2 \mathrm{DM}$ in age-matched men, ${ }^{82}$ suggesting that androgens, like estrogens, may have sex-specific roles in the development of type $2 \mathrm{DM}$ and possibly in the progression of disease complications, such as nephropathy.

\section{CONCLUSIONS}

Although there is still much controversy regarding whether actual sex differences exist in the development and/or progression of diabetic renal disease, the data are clear on the fact that diabetic women exhibit a greater incidence and progression of renal disease compared with nondiabetic women. Some of the possible reasons for the loss of female sex as a 
protective factor against renal disease in diabetes are the reduced concentrations of plasma estradiol, dysregulation of its receptors, and subsequent dysregulation of the cellular pathways estradiol regulates in the kidney. The contribution of sex hormones, particularly estrogens, in the pathophysiology of diabetic renal disease has only recently become a topic of more intensive investigation. Although these studies have provided valuable information on the direct and indirect effects of estrogens in the kidney, further studies are needed to adequately address the relationship between ovarian hormones and the incidence and progression of diabetic renal disease.

\section{References}

1. Seliger SL, Davis C, Stehman-Breen C. Gender and the progression of renal disease. Curr Opin Nephrol Hypertens. 2001; 10:219-225. [PubMed: 11224697]

2. Silbiger SR, Neugarten J. The impact of gender on the progression of chronic renal disease. Am J Kidney Dis. 1995; 25:515-533. [PubMed: 7702046]

3. Neugarten J. Gender and the progression of renal disease. J Am Soc Nephrol. 2002; 13:2807-2809. [PubMed: 12397053]

4. Neugarten J, Acharya A, Silbiger SR. Effect of gender on the progression of nondiabetic renal disease: a meta-analysis. J Am Soc Nephrol. 2000; 11:319-329. [PubMed: 10665939]

5. Jungers $P$, Hannedouche T, Itakura Y, et al. Progression rate to end-stage renal failure in nondiabetic kidney diseases: A multivariate analysis of determinant factors. Nephrol Dial Transplant. 1995; 10:1353-1360. [PubMed: 8538926]

6. Ruggenenti P, Gambara V, Perna A, et al. The nephropathy of non-insulin-dependent diabetes: Predictors of outcome relative to diverse patterns of renal injury. J Am Soc Nephrol. 1998; 9:23362343. [PubMed: 9848788]

7. Hovind P, Tarnow L, Parving HH. Remission and regression of diabetic nephropathy. Curr Hypertens Rep. 2004; 6:377-382. [PubMed: 15341691]

8. Sibley SD, Thomas W, de Boer I, et al. Gender and elevated albumin excretion in the Diabetes Control and Complications Trial/Epidemiology of Diabetes Interventions and Complications (DCCT/EDIC) cohort: Role of central obesity. Am J Kidney Dis. 2006; 47:223-232. [PubMed: 16431251]

9. Jones CA, Krolewski AS, Rogus J, et al. Epidemic of end-stage renal disease in people with diabetes in the United States population: Do we know the cause? Kidney Int. 2005; 67:1684-1691.

[PubMed: 15840014]

10. Jacobsen P, Rossing K, Tarnow L, et al. Progression of diabetic nephropathy in normotensive type 1 diabetic patients. Kidney Int Suppl. 1999; 71:S101-S105. [PubMed: 10412749]

11. Breyer JA, Bain RP, Evans JK, et al. Predictors of the progression of renal insufficiency in patients with insulin-dependent diabetes and overt diabetic nephropathy. The Collaborative Study Group. Kidney Int. 1996; 50:1651-1658. [PubMed: 8914032]

12. Rossing P, Hougaard P, Parving HH. Risk factors for development of incipient and overt diabetic nephropathy in type 1 diabetic patients: A 10-year prospective observational study. Diabetes Care. 2002; 25:859-864. [PubMed: 11978681]

13. Laron-Kenet T, Shamis I, Weitzman S, et al. Mortality of patients with childhood onset (0-17 years) type I diabetes in Israel: A population-based study. Diabetologia. 2001; 44(Suppl 3):B81B86. [PubMed: 11724422]

14. Orchard TJ, Dorman JS, Maser RE, et al. Prevalence of complications in IDDM by sex and duration. Pittsburgh Epidemiology of Diabetes Complications Study II. Diabetes. 1990; 39:11161124. [PubMed: 2384191]

15. Schultz CJ, Konopelska-Bahu T, Dalton RN, et al. for the Oxford Regional Prospective Study Group. Microalbuminuria prevalence varies with age, sex, and puberty in children with type 1 diabetes followed from diagnosis in a longitudinal study. Diabetes Care. 1999; 22(3):495-502. [PubMed: 10097935] 
16. Holl RW, Grabert M, Thon A, Heinze E. Urinary excretion of albumin in adolescents with type 1 diabetes: Persistent versus intermittent microalbuminuria and relationship to duration of diabetes, sex, and metabolic control. Diabetes Care. 1999; 22:1555-1560. [PubMed: 10480525]

17. Mangili R, Deferrari G, Di Mario U, et al. Arterial hypertension and microalbuminuria in IDDM: The Italian Microalbuminuria Study. Diabetologia. 1994; 37:1015-1024. [PubMed: 7851680]

18. Bain R, Rohde R, Hunsicker LG, et al. for the Collaborative Study Group. A controlled clinical trial of angiotensin-converting enzyme inhibition in type I diabetic nephropathy: Study design and patient characteristics. J Am Soc Nephrol. 1992; 3(4 Suppl):S97-S103. [PubMed: 1457767]

19. Muhlhauser I, Bender R, Bott U, et al. Cigarette smoking and progression of retinopathy and nephropathy in type 1 diabetes. Diabet Med. 1996; 13:536-543. [PubMed: 8799657]

20. Coonrod BA, Ellis D, Becker DJ, et al. Predictors of microalbuminuria in individuals with IDDM. The Pittsburgh Epidemiology of Diabetes Complications Study. Diabetes Care. 1993; 16:13761383. [PubMed: 8269796]

21. Rossing P, Tarnow L, Nielsen FS, et al. Short stature and diabetic nephropathy. BMJ. 1995; 310:296-297. [PubMed: 7866171]

22. Dahlquist G, Kallen B. Mortality in childhood-onset type 1 diabetes: A population-based study. Diabetes Care. 2005; 28:2384-2387. [PubMed: 16186267]

23. Mlynarski WM, Placha GP, Wolkow PP, et al. Risk of diabetic nephropathy in type 1 diabetes is associated with functional polymorphisms in RANTES receptor gene (CCR5): A sex-specific effect. Diabetes. 2005; 54:3331-3335. [PubMed: 16249462]

24. Savage S, Nagel NJ, Estacio RO, et al. Clinical factors associated with urinary albumin excretion in type II diabetes. Am J Kidney Dis. 1995; 25:836-844. [PubMed: 7771479]

25. Parving HH, Gall MA, Skott $P$, et al. Prevalence and causes of albuminuria in non-insulindependent diabetic patients. Kidney Int. 1992; 41:758-762. [PubMed: 1513098]

26. Ravid M, Brosh D, Ravid-Safran D, et al. Main risk factors for nephropathy in type 2 diabetes mellitus are plasma cholesterol levels, mean blood pressure, and hyperglycemia. Arch Intern Med. 1998; 158:998-1004. [PubMed: 9588433]

27. Lewis EJ, Hunsicker LG, Rodby RA. A clinical trial in type 2 diabetic nephropathy. Am J Kidney Dis. 2001; 38(4 Suppl 1):S191-S194. [PubMed: 11576953]

28. Keane WF, Brenner BM, de Zeeuw D, et al. The risk of developing end-stage renal disease in patients with type 2 diabetes and nephropathy: The RENAAL study. Kidney Int. 2003; 63:14991507. [PubMed: 12631367]

29. Gall MA, Hougaard P, Borch-Johnsen K, Parving HH. Risk factors for development of incipient and overt diabetic nephropathy in patients with non-insulin dependent diabetes mellitus: prospective, observational study. BNJ. 1997; 314:783-788.

30. Olivarius Nde F, Vestbo E, Andreasen AH, Mogensen CE. Renal involvement is related to body height in newly diagnosed diabetic women aged 40 years or over. Diabetes Metab. 2001; 27:1418. [PubMed: 11240440]

31. Crook ED, Patel SR. Diabetic nephropathy in African-American patients. Curr Diab Rep. 2004; 4:455-461. [PubMed: 15539011]

32. Looker HC, Krakoff J, Funahashi T, et al. Adiponectin concentrations are influenced by renal function and diabetes duration in Pima Indians with type 2 diabetes. J Clin Endocrinol Metab. 2004; 89:4010-4017. [PubMed: 15292342]

33. Young BA, Maynard C, Boyko EJ. Racial differences in diabetic nephropathy, cardiovascular disease, and mortality in a national population of veterans. Diabetes Care. 2003; 26:2392-2399. [PubMed: 12882868]

34. Ginsburg ES, Owen WF Jr, Greenberg LM, et al. Estrogen absorption and metabolism in postmenopausal women with end-stage renal disease. J Clin Endocrinol Metab. 1996; 81:44144417. [PubMed: 8954051]

35. Wang SL, Head J, Stevens L, Fuller JH. Excess mortality and its relation to hypertension and proteinuria in diabetic patients. The world health organization multinational study of vascular disease in diabetes. Diabetes Care. 1996; 19:305-312. [PubMed: 8729151] 
36. Fagot-Campagna A, Nelson RG, Knowler WC, et al. Plasma lipoproteins and the incidence of abnormal excretion of albumin in diabetic American Indians: The Strong Heart Study. Diabetologia. 1998; 41:1002-1009. [PubMed: 9754817]

37. Dorman JS, Steenkiste AR, Foley TP, et al. for the Familial Autoimmune and Diabetes (FAD) Study. Menopause in type 1 diabetic women: Is it premature? Diabetes. 2001; 50:1857-1862. [PubMed: 11473049]

38. Sowers M, Derby C, Jannausch ML, et al. Insulin resistance, hemostatic factors, and hormone interactions in pre- and perimenopausal women: SWAN. J Clin Endocrinol Metab. 2003; 88:49044910. [PubMed: 14557472]

39. Salonia A, Lanzi R, Scavini M, et al. Sexual function and endocrine profile in fertile women with type 1 diabetes. Diabetes Care. 2006; 29:312-316. [PubMed: 16443879]

40. Wells CC, Riazi S, Mankhey RW, et al. Diabetic nephropathy is associated with decreased circulating estradiol levels and imbalance in the expression of renal estrogen receptors. Gend Med. 2005; 2:227-237. [PubMed: 16464734]

41. Lovegrove AS, Sun J, Gould KA, et al. Estrogen receptor alpha-mediated events promote sexspecific diabetic glomerular hypertrophy. Am J Physiol Renal Physiol. 2004; 287:F586-F591. [PubMed: 15149972]

42. Casson IF, Clarke CA, Howard CV, et al. Outcomes of pregnancy in insulin dependent diabetic women: results of a five year population cohort study. BMJ. 1997; 315:275-278. [PubMed: 9274545]

43. Evers IM, de Valk HW, Visser GH. Risk of complications of pregnancy in women with type 1 diabetes: Nationwide prospective study in the Netherlands. BMJ. 2004; 328:915. [PubMed: 15066886]

44. Ding EL, Song Y, Malik VS, Liu S. Sex differences of endogenous sex hormones and risk of type 2 diabetes: A systematic review and meta-analysis. JAMA. 2006; 295:1288-1299. [PubMed: 16537739]

45. Stamataki KE, Spina J, Rangou DB, et al. Ovarian function in women with non- insulin dependent diabetes mellitus. Clin Endocrinol (Oxf). 1996; 45:615-621. [PubMed: 8977760]

46. Kanaya AM, Herrington D, Vittinghoff E, et al. for the Heart and Estrogen/progestin Replacement Study. Glycemic effects of postmenopausal hormone therapy: the Heart and Estrogen/progestin Replacement Study. A randomized, double-blind, placebo-controlled trial. Ann Intern Med. 2003; 138:1-9. [PubMed: 12513038]

47. Friday KE, Dong C, Fontenot RU. Conjugated equine estrogen improves glycemic control and blood lipoproteins in postmenopausal women with type 2 diabetes. J Clin Endocrinol Metab. 2001; 86:48-52. [PubMed: 11231977]

48. Samaras K, Hayward CS, Sullivan D, et al. Effects of postmenopausal hormone replacement therapy on central abdominal fat, glycemic control, lipid metabolism, and vascular factors in type 2 diabetes: A prospective study. Diabetes Care. 1999; 22:1401-1407. [PubMed: 10480500]

49. Ferrara A, Karter AJ, Ackerson LM, et al. for the Northern California Kaiser Permanente Diabetes Registry. Hormone replacement therapy is associated with better glycemic control in women with type 2 diabetes: The Northern California Kaiser Permanente Diabetes Registry. Diabetes Care. 2001; 24:1144-1150. [PubMed: 11423493]

50. Dubuisson JT, Wagenknecht LE, D'Agostino RB Jr, et al. Association of hormone replacement therapy and carotid wall thickness in women with and without diabetes. Diabetes Care. 1998; 21:1790-1796. [PubMed: 9802722]

51. Margolis KL, Bonds DE, Rodabough RJ, et al. for the Women's Health Initiative Investigators. Effect of estrogen plus progestin on the incidence of diabetes in postmenopausal women: results from the Women's Health Initiative Hormone Trial. Diabetologia. 2004; 47:1175-1187. [PubMed: 15252707]

52. Barrett-Connor E, Ensrud KE, Harper K, et al. Post hoc analysis of data from the Multiple Outcomes of Raloxifene Evaluation (MORE) trial on the effects of three years of raloxifene treatment on glycemic control and cardiovascular disease risk factors in women with and without type 2 diabetes. Clin Ther. 2003; 25:919-930. [PubMed: 12852708] 
53. Svensson M, Nystrom L, Schon S, Dahlquist G. Age at onset of childhood-onset type 1 diabetes and the development of end-stage renal disease: A nationwide population-based study. Diabetes Care. 2006; 29:538-542. [PubMed: 16505502]

54. Lane PH. Diabetic kidney disease: Impact of puberty. Am J Physiol Renal Physiol. 2002; 283:F589-F600. [PubMed: 12217849]

55. Shlipak MG, Simon JA, Grady D, et al. for the Heart and Estrogen/progestin Replacement Study (HERS) Investigators. Renal insufficiency and cardiovascular events in postmenopausal women with coronary heart disease. J Am Coll Cardiol. 2001; 38:705-711. [PubMed: 11527621]

56. Szekacs B, Vajo Z, Varbiro S, et al. Postmenopausal hormone replacement improves proteinuria and impaired creatinine clearance in type 2 diabetes mellitus and hypertension. BJOG. 2000; 107:1017-1021. [PubMed: 10955435]

57. Antus B, Hamar P, Kokeny G, et al. Estradiol is nephroprotective in the rat remnant kidney. Nephrol Dial Transplant. 2003; 18:54-61. [PubMed: 12480960]

58. Hadjadj S, Gourdy P, Zaoui P, et al. for the RADIAN Study Group. Effect of raloxifene-a selective estrogen receptor modulator-on kidney function in post-menopausal women with type 2 diabetes: Results from a randomized, placebo-controlled pilot trial. Diabet Med. 2007; 24:906910. [PubMed: 17451421]

59. Tomiyoshi Y, Sakemi T, Aoki S, Miyazono M. Different effects of castration and estrogen administration on glomerular injury in spontaneously hyperglycemic Otsuka Long-Evans Tokushima Fatty (OLETF) rats. Nephron. 2002; 92:860-867. [PubMed: 12399633]

60. Mankhey RW, Bhatti F, Maric C. 17beta-Estradiol replacement improves renal function and pathology associated with diabetic nephropathy. Am J Physiol Renal Physiol. 2005; 288:F399F405. [PubMed: 15454392]

61. Mankhey R, Wells CC, Bhatti F, Maric C. 17-beta Estradiol supplementation reduces tubulointerstitial fibrosis by increasing MMP activity in the diabetic kidney. Am J Physiol-Reg, Integr, Comp Physiol. 2006; 292:R769-R777.

62. Chin M, Isono M, Isshiki K, et al. Estrogen and raloxifene, a selective estrogen receptor modulator, ameliorate renal damage in db/db mice. Am J Pathol. 2005; 166:1629-1636. [PubMed: 15920148]

63. Dixon A, Wells CC, Singh S, et al. Renoprotective effects of a selective estrogen receptor modulator, raloxifene, in an animal model of diabetic nephropathy. Am J Nephrol. 2007; 27:120 128. [PubMed: 17308373]

64. Gallagher CJ, Keene KL, Mychaleckyj JC, et al. Investigation of the estrogen receptor-alpha gene with type 2 diabetes and/or nephropathy in African-American and European-American populations. Diabetes. 2007; 56:675-684. [PubMed: 17327435]

65. von Hertzen L, Forsblom C, Stumpf K, et al. for the FinnDiane Study Group. Highly elevated serum phyto-estrogen concentrations in patients with diabetic nephropathy. J Intern Med. 2004; 255:602-609. [PubMed: 15078503]

66. Ahmed SB, Hovind P, Parving HH, et al. Oral contraceptives, angiotensin-dependent renal vasoconstriction, and risk of diabetic nephropathy. Diabetes Care. 2005; 28:1988-1994. [PubMed: 16043743]

67. Garg SK, Chase HP, Marshall G, et al. Oral contraceptives and renal and retinal complications in young women with insulin-dependent diabetes mellitus. JAMA. 1994; 271:1099-1102. [PubMed: 8151852]

68. Potier M, Karl M, Zheng F, et al. Estrogen-related abnormalities in glomerulosclerosis-prone mice: Reduced mesangial cell estrogen receptor expression and prosclerotic response to estrogens. Am J Pathol. 2002; 160:1877-1885. [PubMed: 12000739]

69. Elliot SJ, Karl M, Berho M, et al. Estrogen deficiency accelerates progression of glomerulosclerosis in susceptible mice. Am J Pathol. 2003; 162:1441-1448. [PubMed: 12707027]

70. Negulescu O, Bognar I, Lei J, et al. Estradiol reverses TGF-beta1-induced mesangial cell apoptosis by a casein kinase 2-dependent mechanism. Kidney Int. 2002; 62:1989-1998. [PubMed: 12427123]

71. Elliot SJ, Karl M, Berho M, et al. Smoking induces glomerulosclerosis in aging estrogen-deficient mice through cross-talk between TGF-beta1 and IGF-I signaling pathways. J Am Soc Nephrol. 2006; 17:3315-3324. [PubMed: 17093064] 
72. Blush J, Lei J, Ju W, et al. Estradiol reverses renal injury in Alb/TGF-beta1 transgenic mice. Kidney Int. 2004; 66:2148-2154. [PubMed: 15569304]

73. Gross ML, Adamczak M, Rabe T, et al. Beneficial effects of estrogens on indices of renal damage in uninephrectomized SHRsp rats. J Am Soc Nephrol. 2004; 15:348-358. [PubMed: 14747381]

74. Dean SA, Tan J, O'Brien ER, Leenen FH. 17beta-Estradiol downregulates tissue angiotensinconverting enzyme and ANG II type 1 receptor in female rats. Am J Physiol Regul Integr Comp Physiol. 2005; 288:R759-R766. [PubMed: 15550614]

75. Xiao S, Gillespie DG, Baylis C, et al. Effects of estradiol and its metabolites on glomerular endothelial nitric oxide synthesis and mesangial cell growth. Hypertension. 2001; 37:645-650. [PubMed: 11230350]

76. Neugarten J, Acharya A, Lei J, Silbiger S. Selective estrogen receptor modulators suppress mesangial cell collagen synthesis. Am J Physiol Renal Physiol. 2000; 279:F309-F318. [PubMed: 10919851]

77. Tofovic SP, Dubey RK, Jackson EK. 2-Hydroxyestradiol attenuates the development of obesity, the metabolic syndrome, and vascular and renal dysfunction in obese ZSF1 rats. J Pharmacol Exp Ther. 2001; 299:973-977. [PubMed: 11714885]

78. Zhang X, Jia Y, Jackson EK, Tofovic SP. 2-Methoxyestradiol and 2-ethoxyestradiol retard the progression of renal disease in aged, obese, diabetic ZSF1 rats. J Cardiovasc Pharmacol. 2007; 49:56-63. [PubMed: 17261964]

79. Haffner SM, Katz MS, Stern MP, Dunn JF. The relationship of sex hormones to hyperinsulinemia and hyperglycemia. Metabolism. 1988; 37:683-688. [PubMed: 3290626]

80. Andersson B, Mattsson LA, Hahn L, et al. Estrogen replacement therapy decreases hyperandrogenicity and improves glucose homeostasis and plasma lipids in postmenopausal women with noninsulin-dependent diabetes mellitus. J Clin Endocrinol Metab. 1997; 82:638-643. [PubMed: 9024268]

81. Lindstedt G, Lundberg PA, Lapidus L, et al. Low sex-hormone-binding globulin concentration as independent risk factor for development of NIDDM. 12-yr follow-up of population study of women in Gothenburg, Sweden. Diabetes. 1991; 40:123-128. [PubMed: 2015967]

82. Haffner SM, Dunn JF, Katz MS. Relationship of sex hormone-binding globulin to lipid, lipoprotein, glucose, and insulin concentrations in postmenopausal women. Metabolism. 1992; 41:278-284. [PubMed: 1542267] 